\title{
UN CRÍTICO EN FORMACIÓN: LOS PRIMEROS AÑOS DE LA CRÍTICA DE ANTONIO CANDIDO
}

\author{
Rebeca Errázuriz Cruz \\ Universidad Adolfo Ibáñez, Santiago de Chile, Chile \\ rebelais@gmail.com
}

\section{RESUMEN / ABSTRACT}

El siguiente artículo pretende trazar un recorrido por los primeros años de la obra de Antonio Candido, entre 1941 y 1945 . El objetivo es identificar los rasgos principales de lo que él llama su "crítica funcional" y comprender los problemas teórico-metodológicos que lo llevarán a abandonar este tipo de crítica.

Palabras clave: Antonio Candido, crítica literaria, literatura brasileña, sociología literaria, historia intelectual.

\section{BECOMING A CRITIC: THE EARLY YEARS IN THE WORK OF ANTONIO CANDIDO}

The following article pretends to describe the first years of the work by Brazilian critic Antonio Candido between 1941 and 1945. The purpose is to identify the main features of what he calls his "functional critique" and to understand the theoretical and methodological difficulties that will led him to abandon this kind of critique.

KEYWORDS: Antonio Candido, literary criticism, Brazilian literature, Sociology of literature, Intellectual History. 


\section{INSTALACIÓN DE UN PROYECTO}

En 1941, Antonio Candido estrenó su primer trabajo como crítico literario en la revista Clima, fundada junto a un grupo de intelectuales que llegarían a ser figuras centrales de la nueva generación crítica de São Paulo ${ }^{1}$. En 1943, la incipiente carrera del joven sociólogo ganaría un nuevo impulso como "crítico oficial" en el diario Folha da Manhã. Los primeros años de ejercicio de Candido son cruciales para entender el largo viaje que lo transformará en uno de los intelectuales más influyentes de Brasil, sin embargo, es poco lo que se ha investigado sobre esta primera etapa. El propio Candido nunca quiso publicar una buena parte de sus notas de prensa porque consideraba superada esta etapa formativa. El hito que cierra esta fase es su tesis de "livre docencia” Introdução ao método crítico de Sílvio Romero, de 1945. En el prefacio a la segunda edición de dicha obra su autor comenta:

Publico-o, em grande parte, por motivo pessoal, isto é: marcar o ponto de partida das posições críticas a que cheguei, pois foi escrevendo esta tese que as defini pela primeira vez de maneira sistemática, após os primeiros anos de tateio em revistas e jornais, orientado apenas pela alegre confiança dos vinte anos e algumas ilusões que aqui superei, mas que até hoje me são atribuídas. Superei-as graças ao contato com certas obras inglesas e americanas, registradas na bibliografia, e pela verificação prática da insuficiência dos pontos de vista que inicialmente procurei aplicar $(O \text { método } 12)^{2}$.

El proyecto crítico de Candido sufre un viraje notorio como consecuencia de la experiencia de redacción de esta tesis y bajo la creciente influencia de sus lecturas a mediados de 1944 sobre T. S. Eliot y el new criticism. Esta fase podría caracterizarse como el período de la "crítica funcional", término utilizado por el crítico para explicar su perspectiva de ese entonces. En este artículo nos proponemos realizar un análisis de esta primera etapa formativa, rastreando sus primeros tanteos y las ilusiones superadas.

Sobre Antonio Candido y el grupo Clima, véase el trabajo de Heloisa Pontes Destinos mistos: os críticos do Grupo Clima em São Paulo 1940-1968.

$2 \quad$ El prefacio corresponde a la segunda edición, publicada en 1961. 
Para comenzar, es necesario revisar tres textos que pueden ser considerados programáticos: la primera entrega para $\mathrm{Clima}^{3}$, la primera nota de crítica literaria para Folha da Manhã $\tilde{y}^{4}$ las declaraciones recogidas en "Plataforma da nova geração" . Antonio Candido escribió estos textos en diferentes momentos y dan cuenta de la progresiva definición y afianzamiento de su proyecto crítico. En su primer texto para Clima, "Livros", se presenta ante sus lectores como un crítico joven que pretende ocuparse de la nueva literatura brasileña. Desea instalar una mirada propia y con ella abrir un lugar para la voz del joven crítico al interior del campo literario, pero toma ese lugar con responsabilidad y cautela. El autor establece cuáles serán los principios rectores de su trabajo:

Uma crítica, entretanto, que se queira ater apenas ao fenômeno individual do escritor em questão, sem relacioná-lo organicamente com o complexo de ideias que caracterizam o momento social, me parece insuficiente e mesquinha. $\mathrm{O}$ escritor, embora ressalvadas as suas qualidades puramente pessoais, reflete sempre um estado de alma ou de espírito mais ou menos geral. E o crítico pode colocar-se em face do escritor ou em face da realidade complexa escritor-meio. Creio poder dizer que esta é a nossa tendência. Crítica sub-specie societatis? Nem tanto. De qualquer maneira, porém, crítica que se nega a ver no autor uma entidade independente; que pretende sentir as suas ligações profundas com o tempo, com o grupo social em função do qual trabalha e cria (108).

Candido pretende abordar la obra literaria como una manifestación de las condiciones y conflictos propios de su época y salta a la vista la ausencia de cualquier referencia al carácter estético de la literatura. En efecto, hay que tener en cuenta que la creciente politización al interior del campo literario brasileño a partir de 1930 tuvo como consecuencia que la crítica y los autores se desplazaran hacia tendencias cada vez más ideologizadas, dejando de lado una de las novedades aportadas por los modernistas: la discusión de la literatura como objeto estético. El proyecto estético de los años veinte dio paso a un proyecto político-ideológico en los treinta, con una pérdida de equilibrio en el enfoque (Lafetá 252). Dado lo anterior, no es raro que plantee una postura

\author{
Mayo de 1941. \\ 7 de enero de 1943. \\ Texto publicado por O Estado de São Paulo el 15 de julio de 1943.
}


de esta índole, pues en el escenario de una crítica dividida entre la afirmación del individuo y la libertad impresionista, por un lado, y el compromiso con la sociedad, es decir, con la acción política, por otro; opta por este último. Candido se opone a ver la literatura como un fenómeno meramente individual cuya finalidad última es despertar una experiencia de placer o una revelación espiritual en el lector, para él la literatura es un fenómeno sociocultural que expresa un compromiso político.

Un segundo texto programático es "Ouverture", la primera de sus "Notas de crítica literária” para Folha da Manhã. Allí señala que generalmente se espera del crítico que defina en qué consiste su oficio y dé ciertas garantías acerca de su ética, sin embargo, declara que no hará ni lo uno ni lo otro: no posee una teoría sobre lo que pueda ser la crítica y prefiere dejar la cuestión de la ética al juicio de sus lectores. No obstante, esto no le impide plantear una primera exigencia al trabajo crítico, la necesidad de trascender el plano subjetivo: "a tarefa do crítico será por ventura mais de integrar a significação de uma obra no seu momento cultural do que, tomando-a como um pretexto, procurar tirar dela uma série de variações pessoais" (Textos 25). Candido entiende la crítica como una "tarea", lo que implica consecuencias éticas y políticas. A pesar de que ha afirmado que no nos dará una definición de la crítica, en realidad sí lo hace, solo que su definición no es teórica sino práctica: la crítica es una actividad que atiende a una necesidad y que conlleva una responsabilidad. La crítica como tarea implica que ésta deviene una necesidad de primer orden, vinculada a la exigencia de ligar la dilucidación de la obra literaria a su momento cultural. El autor critica duramente a quienes, bajo la excusa de una apertura frente a las sugestiones de la obra, recusan tomar partido o manifestar claramente una posición ética, política o filosófica (Textos 27). El goce estético de la obra es visto como una suerte de lujo al que el crítico no se puede entregar sin pecar de individualismo y desidia. Es deber del crítico hacerse útil y realizar un análisis de la literatura que permita al lector comprender mejor el pasado, el presente y las posibilidades del futuro. En suma, el crítico se hace útil, pues su análisis transforma a la literatura en un medio de conocimiento de la realidad, la cultura y el entorno histórico y social: "o esforço para esclarecer os acontecimentos presentes é a obrigação primeira do intelectual (...) a crítica -literária, artística, filosófica, científicanos aparece como um instrumento de conhecimento e um guia de caminhos difíceis, e a sua utilidade não pode ser negada" (Textos 28).

El deseo de actuar como un intelectual comprometido implica que el objeto estético analizado queda en una posición ancilar con relación al fin 
último de comprender una época de crisis. Ahora bien, esto no significa que el plano estético desaparezca; para quien lee a Candido es evidente la preocupación que muestra por la factura estética de la obra. El problema no es la eliminación del aspecto estético, sino su relegación a un segundo plano como momento crítico necesario pero insuficiente, que debe ser trascendido para poder dilucidar el significado de la obra con relación a su contexto. Candido casi nunca llega a elogiar obras evidentemente panfletarias y el valor estético es, en general, condición sine qua non a la hora de evaluar cualquier tipo de literatura, pero, así como es condición necesaria no es suficiente y el juicio de nuestro crítico será muchas veces discutible ${ }^{6}$.

El apremio por el compromiso político es explícito en el texto "Plataforma da nova geração" ". Uno de los asuntos más interesantes de este artículo es su visión sobre las generaciones que lo preceden: los escritores de la década del veinte y el treinta. Hay una reflexión sobre el significado histórico del modernismo en la que Candido toma distancia de las actitudes rebeldes y polemistas de los escritores del 22, sin negar por ello su aporte e importancia. Cree que no fueron capaces de superar una actitud que tuvo sentido en su momento, pero que en la actualidad peca de ser un tanto superflua. Aunque concede a los escritores del 22 la ganancia de una libertad artística, le parece que se quedaron estancados en esa conquista ${ }^{8}$. Candido relaciona la actitud estética de los modernistas con el individualismo y la falta de seriedad, y

6 Ramassotte comenta: "Nessa altura, os juízos estéticos de Candido estavam claramente subordinados a preocupações de ordem político-ideológica e, por conseguinte, talvez seja mais adequado qualificar a modalidade da intervenção intelectual praticada por ele na grande imprensa como uma crítica literária de fundo sociológico e politicamente orientada, cujos critérios de apreciação valorativa se condicionam, em boa medida, à maior ou menor contribuição das obras para o debate das ideias em conflito em seu tempo" (Ramassote 7778). Hasta donde sabemos, el excelente trabajo de Ramassote es quizás uno de los pocos que no se resta a admitir que existe una inclinación sociológica y política que afecta, a veces para mal, el juicio de Candido durante esta primera fase de su obra.

Publicado el 5 de julio de 1943 en O Estado de São Paulo, este artículo es la respuesta a un cuestionario de Mário Neme dirigido a distintos jóvenes destacados, con el fin de indagar sobre los rasgos comunes de esta nueva camada intelectual.

"A gente de 22, que é mais ou menos a dele, prestou um grande serviço ao Brasil, tornando possível a liberdade do escritor e do artista. Mas os que conseguiram tal coisa, à custa de quanta luta e quanto barulho, se esgotaram quase todos na tarefa. Poucos tiveram força para arrancar a sua obra ao experimentalismo hedonístico, e se perderam na piada, na virtuosidade e na ação política reacionária, isto é, o tipo de política tendente a preservar as gracinhas literárias e o exibicionismo intelectual” (Textos 239). 
muestra un rechazo sistemático a las vanguardias y al experimentalismo9. En contraste, defiende la idea de un intelectual "funcional", cuya obra esté al servicio de la comprensión de la realidad brasileña. En ese sentido, Candido se considera mucho más cercano a los intelectuales de 1930:

Para falar a verdade, com os de 30 é que começa a literatura brasileira. Surgem os escritores que pouco devem ao modelo estrangeiro, os estudiosos que começam a sistematizar o estudo do Brasil e proceder a análise generalizada dos seus problemas. A geração de 20 foi mais um estouro de "enfants-terribles". Tem muito do personalismo faroleiro de Oswald de Andrade, que qualificava a si mesmo de "palhaço da burguesia", ao encetar uma fase mais funcional da sua carreira. A de 30 é o historicismo grande-burguês de Gilberto Freyre, e é também o realismo histórico de Caio Prado Júnior (...). Nós nos formamos sob seu influxo e somos em grande parte o seu resultado. A nossa orientação intelectual se delineia na atmosfera das suas lutas políticas, dos seus partidos extremos (Textos 240).

La mirada volcada hacia adentro y la perspectiva crítica son los atributos con los que Candido se identifica, cuestión que se hace evidente cuando declara que la literatura brasileña realmente comienza en 1930 porque solo entonces se libró de las influencias extranjeras que cultivaron los modernistas de la primera hora. Otro elemento central es la orientación de la reflexión hacia lo colectivo, cuestión que no observa en lo que él califica como el individualismo hedonista de los modernistas del 22.

En síntesis, podemos ver cómo estos tres textos dan cuerpo a un programa crítico. Candido va construyendo un lugar de enunciación propio que posee ciertas singularidades. En un campo cultural entrecruzado por diversas disputas políticas, religiosas y sociales, afirma que el intelectual posee una tarea ética ineludible: asumir un compromiso en relación con la realidad sobre la cual se reflexiona. Este compromiso es el núcleo de su "crítica funcional": una crítica útil a las necesidades del momento y que busca entregar claves para esclarecer los fenómenos sociales a través del análisis de la literatura. He aquí el corolario del proyecto crítico de Antonio Candido. Nos resta ver cómo se

$9 \quad$ El caso más emblemático es la opinión de Candido sobre Oswald de Andrade. Analizamos en detalle este caso en el artículo "Antonio Candido y el problema de la tradición: el lugar de Oswald de Andrade”. Véase Errázuriz 2014. 
pone en obra, cuáles son sus tensiones internas y las fisuras que anuncian el giro de su pensamiento a inicios de 1945.

\section{FORTUNAS Y DESVENTURAS DE LA CRÍTICA FUNCIONAL}

Para comentar la producción de este periodo, un buen punto de partida es la nota "Ficção I" 10 , la primera de una serie en la que Candido explica cuál es el criterio que utiliza para juzgar una obra y lo aplica al caso de Dois Mundos ${ }^{11}$. Este análisis se ofrece como ejemplo de una obra que no es funcional -mero ejercicio de estilo y preciosismo verbal- y sirve como contraste frente a $O$ resto é silêncio, novela de Érico Veríssimo que, pese a su lenguaje sencillo, vale por su carácter necesario. El análisis de la obra de Veríssimo ocupa las siguientes dos notas ${ }^{12}$, de modo que "Ficção I" tiene la función de exponer un método y aplicarlo a un primer caso, mientras que las siguientes notas muestran la aplicación del mismo método a un segundo caso. El comentario sobre $O$ resto é silêncio fue publicado con el título "Romance popular" en el primer libro de Antonio Candido, Brigada Ligeira (1945). Sin embargo, de las tres notas que componen la serie solo las dos últimas fueron incluidas en "Romance popular": mientras "Ficção I" fue completamente omitido", "Fiç̧ão II" y "Ficção III" aparecen refundidos y casi sin modificación. Creemos que la omisión del primero se debe a que consiste en una exposición de los fundamentos de la crítica funcional, que para 1945 Candido ya había abandonado. "Ficção I" comienza diciendo:

Se me perguntarem qual é o critério objetivo mais firme e mais imediato para se julgar uma obra de arte ou de literatura, eu direi que é o critério da sua necessidade. Necessidade, neste sentido, quer dizer a presença de uma série de razões que fazem com que a obra pareça alguma coisa que não poderia deixar de existir (...). Este caráter é dado

$10 \quad$ Publicada en Folha da Manhã el 4 de febrero de 1943.

11 Colección de cuentos de Aurélio Buarque de Hollanda publicada en 1942.

12 "Ficção II", del 11 de febrero de 1943 y "Ficção III", del 18 de febrero del mismo año.

13 Vinicius Dantas, organizador de la completísima bibliografía de Antonio Candido, pese a ser prácticamente infalible omite la ausencia de "Ficção I" en el artículo "Romance popular". Véase Dantas 54. 
à obra por um conjunto de fatores, tanto internos quanto externos, que se reúnem, afinal das contas, para definir a sua funcionalidade, isto é, a sua razão de ser em função de certos problemas ou, simplesmente, certas características do homem ou da sociedade de uma época (5).

La argumentación de Candido sirve como prolegómeno a su comentario sobre la obra de Veríssimo, quien era menospreciado por ser un escritor popular de lenguaje sencillo, desprovisto de artificios y accesible para un público lector más amplio. En "Romance popular" Candido concluye: "não entendo literatura em que não haja um escritor suficientemente popular para, sem quebra de nível, desempenhar junto ao povo o papel social que incumbe a arte" (72). La defensa del papel social del arte, en este caso, sería su capacidad de ofrecer una representación del mundo dirigida al pueblo mismo, el cual es capaz de comprender la realidad en que vive a través de la novela. Por lo tanto, el gran aporte de Veríssimo sería su capacidad de escribir novelas para el pueblo, sin que eso signifique que dichas obras tengan un nivel inferior. Candido aclara que no toda novela, por ser popular, es una buena novela. Ahora bien, así como una novela popular no tiene por qué ser estéticamente inferior, tampoco podemos afirmar que una novela se justifique por el mero hecho de ser popular. El crítico distingue, entre las obras de Veríssimo, novelas de un alto nivel-Clarissa (1933), Um lugar ao sol (1936) y O resto é silêncio-y novelas donde el nivel decae, como Saga (1940) y Olhai os lírios do campo (1938). El criterio que permite discernir entre uno y otro grupo es de orden estético, es decir, no juzga el carácter socialmente necesario de las novelas ni sus contenidos, sino la forma en que estos han sido presentados (67). Candido hace un notable análisis de las características que hacen de $O$ resto é silêncio una gran novela: "Numa frase-resumo, eu diria que a configuração estrutural deste livro é o problema da interferência dos indivíduos na confluência do tempo. Os destinos individuais -que se entrelaçam, se cruzam, influem uns sobre outros-se ordenam e se esclarecem nele à luz de dois fatores principais: a sua participação e a sua história" (69).

Sorprende la agudeza de este análisis y reconocemos en él al Candido de la dialéctica del malandraje, al que identifica en la estructura misma de la novela una puesta en forma de la organización del mundo ficcional; esos elementos están aquí como anunciando lo que nuestro crítico llegaría a ser en su madurez. El artículo "Romance popular" sobrevive a los presupuestos de la crítica funcional porque, en última instancia, el análisis de Candido está fundado en las cualidades estéticas de la novela, en su forma de presentación 
de un mundo y no en su necesidad. Recordemos que este artículo tiene como objetivo explicar por qué Veríssimo es un escritor de valía, pese a ser popular y a utilizar un lenguaje llano. Candido responde que es un gran novelista justamente por su capacidad de presentar un mundo a través de las interrelaciones de los personajes suspendidos entre su pasado y su futuro, por ende, la valía estética no se basa en el uso de un lenguaje alambicado, sino en las estrategias de composición de la novela como un todo articulado. La cuestión es bastante clara para cualquier lector del artículo publicado en Brigada Ligeira, pero quien lea "Ficção I" se dará cuenta de que Candido no quiso hacer un análisis estético sino uno funcional, tal como lo declara abiertamente en la primera nota de la serie, y si pudo cercenar el prolegómeno metodológico de su análisis fue porque éste no era necesario y era, incluso, contradictorio o al menos accesorio y prescindible en relación con la lectura crítica que él mismo ofrece. Que nuestro autor no fuera consciente de esto al momento de escribir esta serie para Folha nos muestra hasta qué punto la contradicción entre crítica funcional y estética era un problema que estaba presente en su trabajo, pues su intuición de crítico lo lleva a conclusiones que no se extraen de los principios analíticos propuestos. Pero volvamos a "Ficção I". Allí afirma que el criterio más objetivo para juzgar una obra de arte es su necesidad, es decir, el hecho de que la obra sea funcional a su época. Este criterio puede ser, si no objetivo, al menos perfectamente válido; siempre que no se erija como criterio único del valor de la obra. El problema es que, justamente, eso es lo que Candido propone:

Agora, é claro que ao caráter funcional da produção literária vem ligar-se o seu valor próprio. Este, porém, depende em grande parte daquele. Sendo a arte, de modo geral, um fenômeno de antecipação nas esferas do conhecimento o valor de uma obra é inseparável deste aspecto de resposta a uma incógnita - de que acima falei. Prefiro, pelo menos neste caso e com esta acepção, não considerar um valor como qualquer conteúdo irredutível e absoluto de uma criação ou de uma atitude - mas ver nele tomar como critério para encará-lo, a natureza e as propriedades das suas relações com o esforço humano de clarear as franjas de sombra que rodeiam o pobre círculo do conhecimento. Quando, portanto, uma produção do homem vem responder a este esforço de penetração, seja uma máquina que permite um domínio maior sobre a natureza, seja um poema que torna mais claro um canto qualquer da alma - podemos dizer que o seu aparecimento foi necessário, porque ela se integra funcionalmente no conjunto das atividades de uma cultura. Quando se vê que numa obra literária 
nada responde a nada; coisa alguma existe que permita sentir a sua eficiência artística - podemos dizer sem medo que esta obra é desnecessária (Ficção I 5).

Para Candido el análisis literario tiene, en última instancia, una función cognoscitiva que le permite ser útil y por esta razón es fácil ver cómo la literatura desempeña un papel secundario como simple medio para la comprensión de fenómenos sociales. La literatura es encarada como fenómeno social, lo que no es errado puesto que es un fenómeno social. El problema es que Candido pretende transformar este tipo de análisis en una estrategia para discernir el valor de una obra, supeditado a su mayor o menor adecuación a ciertas necesidades sociales, las que, a su vez, son identificadas a partir de un criterio ideológico, ajustado a las sensibilidades socialistas del crítico.

La dimensión estética no es completamente olvidada, sin embargo, para Candido este aspecto no es el determinante último del valor, sino que permite comprender cómo ciertas formas literarias son más adecuadas que otras a las necesidades del momento. La ilustración más clara podemos encontrarla en su marcado rechazo a las vanguardias y su distancia frente al movimiento modernista brasileño es parte de ese rechazo. En contraste, Candido da preferencia a las obras realistas, entendiendo por realismo la capacidad que una obra tiene para representar un todo social dinámico, históricamente determinado e internamente diferenciado. Su preferencia por la forma realista nos permite comprender su rechazo a las vanguardias, pues éstas privilegian un experimentalismo que destruye las formas de representación. En literatura brasileña, Candido prefiere las obras que se ocupan de la representación de la sociedad brasileña en su complejidad y en sus conflictos internos, y se muestra reacio a los escritores que adhieren a un cosmopolitismo propio de las élites y que representan la decadencia de la oligarquía brasileña como el resultado de una crisis espiritual y subjetiva. Para Candido esto equivale a una representación fragmentaria de la realidad, pues la crisis de la burguesía no queda enmarcada dentro de un todo social que le dé un sentido al interior de un devenir histórico. Esta posición de Candido posee ciertas semejanzas con algunas ideas de Gyorgy Lukács: ambos coinciden en su concepción de la novela realista como la forma literaria más perfecta por su correcta adecuación a la realidad representada. Para el húngaro, el realismo es la única forma de representación capaz de dar cuenta de la totalidad social en su complejidad y en sus contradicciones internas, que se muestran en su carácter dinámico $\mathrm{y}$, por lo tanto, históricamente determinado. La novela 
realista procura mantener un equilibrio entre la interioridad del sujeto y el plano objetivo de las acciones inmersas en un mundo social con el que el personaje debe habérselas. En otras palabras, lo real aparece representado a través de una mediación dinámica y no esquemática, que se apoya en una forma de representación capaz de dar cuenta de la totalidad dinámica de lo real $^{14}$. Es por ello que Lukács fue tajante al rechazar las innovaciones de los diferentes modernismos europeos ${ }^{15}$. Si bien es claro que existen diferencias importantes entre Candido y Lukács en cuestiones como la concepción de la necesidad social de una obra ${ }^{16}$, en términos esquemáticos hay una convergencia en su visión de las vanguardias y el realismo.

Para comprender mejor el apego de Candido a la novela realista conviene revisar uno de sus artículos tempranos, "O Romance vendeu a sua alma"17, donde expone sus ideas sobre los atributos esenciales de la novela y hace un diagnóstico crítico de la evolución del género. Allí Candido denuncia un fenómeno actual de la literatura cuyas raíces se remontan a Flaubert y que consiste en la progresiva pérdida de lo que él ve como el "alma" del arte novelesco. Según el autor, lo específico de la literatura no estriba en la experimentación lingüística; al contrario, es justamente esta tendencia la que ha hecho que la literatura pierda su norte al querer incorporar los procesos de otras artes como la música y la pintura. Ya sea a través de la senda del

14 Véase, por ejemplo, el contraste entre realismo y naturalismo en "¿Narrar o describir?" (Lukács, Problemas 171-216). El problema también es expuesto en su respuesta a Bloch "Se trata del realismo" (Lukács, Problemas 288-318).

15 Véase Lukács, Significación 20.

16 Para Candido el carácter funcional de una obra es concebido de manera sencilla e inmediata en la medida en que la obra se ajusta a una necesidad específica del momento: comprender adecuadamente el todo social. Esto implica que una obra puede ser necesaria en un cierto momento y no necesaria en otro: el carácter de necesidad es siempre transitorio. En cambio, para Lukács una obra puede responder a una necesidad social y, sin embargo, no ofrecer una representación adecuada: "Comprender la necesidad social de un estilo determinado no es lo mismo que valorar estéticamente las consecuencias artísticas de dicho estilo. En estética no rige el lema: 'Comprenderlo todo significa perdonarlo todo"' (Problemas 181). Si analizamos las características que definen el carácter necesario de una obra a ojos de Candido, vemos que esas características tienden a coincidir con lo que Lukács considera como una representación adecuada o no alienada de lo real. La diferencia es que para Candido esa adecuación puede tener un carácter relativamente transitorio, lo que le permite aceptar el papel que las vanguardias cumplieron en el pasado y a la vez rechazarlas como inadecuadas a las necesidades del presente.

17 Publicado en la revista Clima en noviembre de 1941. 
naturalismo, que desea transformar la novela en documento científico, o por la senda opuesta de las vanguardias, que buscan pervertir la palabra para arrancarle efectos musicales o pictóricos; la novela se ha perdido a sí misma (27). Para Candido, la sustancia misma de la novela es la trama, el relato de una buena historia verdaderamente novelesca. Los demás elementos, como la dimensión subjetiva de los personajes o los aspectos documentales, bien pueden estar presentes, pero siempre supeditados a una trama que les da su unidad. La dimensión subjetiva de los personajes es necesaria, pero debe tener su justo lugar, en constante equilibrio con el detalle externo. Ese equilibrio se logra justamente porque ambos aspectos quedan supeditados a la trama que da orden y sentido a los elementos, creando con ello un mundo vivo. A su vez, ese mundo no requiere de la glosolalia o del preciosismo verbal, que nuestro autor juzga como un exceso innecesario. Estamos aquí frente a una defensa de la novela realista y Candido encuentra su modelo ideal en Stendhal:

Não conheço ninguém menos artístico que Stendhal, e, em literatura, ninguém mais verdadeiramente artista que ele. É que a sua arte está onde deve estar: na transposição para o plano do romance (...) E isto, Stendhal obtém com o mais sóbrio, parcimonioso e desataviado dos estilos, por vesses desgracioso em sua absoluta despretensão, em sua absoluta falta de sensualidade estilística. Stendhal, porém, sabe criar o mundo para os seus personagens; sabe dispor o detalhe material necessário à sua verdade" (30-31).

En este pasaje estamos ante la presencia de un Antonio Candido estrictamente estético, donde no hay asomo de la crítica funcional. Y encontramos aquí uno de los conceptos que serán centrales en el devenir de su crítica, el de "trasposición". Candido explica aquí -y lo hará también en otros escritos de esta época- ${ }^{18}$ que la novela no constituye una simple reproducción de

18 Véase "Notas à margem de Donana Sofredora" donde vuelve a recordarnos a Lukács: "Uma fatalidade que pesa sobre aqueles que se atem à rigorosa imitação da vida é a impossibilidade de criar personagens. Para dar vida a um personagem, é preciso realizar uma síntese sobre os dados imediatos da vida. É preciso elevar-se a um certo grau de generalidade que torne o personagem ao mesmo tempo típico e universal (universal porque típico). Trasposto sem retoque da vida para a arte o personagem nunca se elevará a tipo. Não passará jamais de um aspéto [sic]" (99). Asimismo, en la nota "Vitaminose" comenta: "A atitude deformadora da arte e da literatura não significa contrafação nem ignorância da realidade. Muito pelo contrário. O material dos livros de ficção é a vida, está claro. Ela é, porém, o ponto de partida. O que interessa, no caso, não é ela, mas a atitude de escolha assumida pelo escritor. O escritor 
la realidad, sino la creación de un mundo independiente, organizado según ciertos criterios estéticos de composición que le dan una forma al relato. A su vez, juzga las diferentes ramas evolutivas del género como una progresiva degradación y pérdida de lo más propio de la novela, debida a la hipertrofia de la dimensión subjetiva (psicologismo), de la objetiva (naturalismo) o del medio expresivo (glosolalia). Este diagnóstico lo lleva a denunciar otro problema: la desaparición de la novela como obra de arte universal, capaz de trascender su propia época y ofrecernos una visión de lo humano que sea eterna. Para Candido este fenómeno tiene su origen en dos causas: por un lado, acusa la aparición de una literatura con fines netamente comerciales, hecha para producir emociones fáciles; por otro, lamenta la pérdida de la autonomía de la literatura como arte específico. Candido ve en el psicologismo, el naturalismo y los modernismos la invasión de otros discursos en el campo de la literatura y critica la intromisión de diferentes corrientes del saber como el positivismo, el bergsonismo, el espiritualismo católico, el psicoanálisis, la política y la sociología; que limitan la novela al utilizarla como instrumento ilustrativo. Candido constata que esta invasión se debe a las características de la época actual, que obliga a utilizar la literatura como un instrumento para pensar y dar respuesta a los problemas de nuestros tiempos:

A culpa destas traições é dupla: de um lado, a necessidade de usar o romance como um instrumento, cômodo pela sua plasticidade e elasticidade, de sondagem e exposição de problemas angustiosos desta época, de ordem individual e de ordem coletiva (...) não nos é mais possível deixar de participar deste ritmo coletivo que nos tira a liberdade e a solidão. E, ao escrever, somos obrigados, quase sem querer, a tratar dos problemas em foco, a prover as exigências da hora. De que maneira fugir a uma onda que nos leva juntos? (28).

Encontramos aquí algunas pistas del conflicto que vive Candido entre la crítica funcional y la estética. El autor afirma que en el presente, la novela, invadida por diversos saberes que le son ajenos, no puede sino someterse a este mal, incluso a costa de su propia desaparición, puesto que los problemas acuciantes de la actualidad la han llevado a cargar con esta función. Y termina

não registra: escolhe. E nesta seleção por ele operada está a base da mencionada deformação artística, porque ela é uma mise em relief do sistema de traços e de valores que vão constituir a verdade da arte, ao lado e acima da verdade da vida" (5). 
por incluirse a sí mismo en este problema: en un comienzo nos habla de "el escritor moderno", pero al describir las penurias de su época pasa a hablarnos en primera persona plural. Cuando declara que "ao escrever, somos obrigados, quase sem querer, a tratar dos problemas em foco", comprendemos que su opción por la crítica funcional no le es del todo grata y la siente más bien como el sacrificio necesario al servicio de una causa ética y política. Detectamos el conflicto del crítico, desgarrado entre su amor por el arte y su deber frente a su sociedad y frente al presente. Es por eso que elogia el coraje de quienes sacrifican la belleza: "E, pensando bem, há, em profundidade um certo heroísmo nos escritores dignos de tal nome que se fazem representantes do gosto do tempo; nos escritores que "renunciando à duração, se dedicam a lidar com problemas do momento, trazendo a eles a contribuição da sua inteligência" (29).

En suma, podemos ver que Candido juzga a las vanguardias bajo dos criterios de diferente orden y que a veces se confunden: el ideológico y el estético. Por una parte, rechaza a las vanguardias por no ser funcionales, afirma que tuvieron una función en su momento como respuesta espontánea a una crisis, pero ésta ya pasó y su forma de encarar los problemas sociales es hoy inadecuada, pues conduce al individualismo. Por otro lado, bajo una mirada estética, las vanguardias serían una traición a los atributos esenciales de la novela encarnados en el equilibrio de la ficción realista. Bajo el criterio ideológico, las vanguardias quedan invalidadas por ser inactuales e incurrir en un individualismo pernicioso, y dicha invalidez es juzgada a través de una estrategia crítica que admite el carácter transitorio de toda obra literaria a la luz de su funcionalidad. Desde el punto de vista estético, en cambio, hay obras hechas para trascender su tiempo, que presentan un mundo que es a la vez vivo y eterno por ser capaz de expresar, a través de una trasposición artística, el carácter universal de lo humano. Candido oscila entre estos dos criterios e incluso los confunde, a ratos privilegia el criterio funcional, pero en otras ocasiones se cuela el punto de vista estético y como lectores es difícil discernir si el autor emite sus juicios desde uno u otro punto de vista.

\section{LA IRRUPCIÓN ESTÉTICA: FISURAS EN LA CRÍTICA FUNCIONAL}

El año 1944 es crucial en la crítica de Antonio Candido; a partir de ese año ha comenzado a leer a algunos autores vinculados al new criticism que despiertan su interés y alteran su perspectiva: Rene Wellek, I. A. Richards y 
Cleanth Brooks ${ }^{19}$. La primera alusión de Candido al new criticism aparece en la nota "Um ano" ${ }^{20}$, donde confirma su opción por la crítica funcional, aunque con algunos alcances interesantes:

Tenho, sobretudo, a alegria de achar que vou mais ou menos cumprindo o meu intento de chamar a atenção do leitor para aspectos pouco lembrados pela nossa crítica, quais sejam o sentido e o condicionamento histórico-social da criação e da obra de arte. E nisso se contem a confiança que nutro na minha utilidade - porque, procurando menos lançar-me no Tempo do que trabalhar, num sentido de interesse coletivo, a minha parcela de tempo, estou transformando a minha crítica em vida de todo o dia (Textos 32).

La relación entre literatura y vida se reitera a lo largo de esta nota y aunque continua definiendo su crítica como funcional, es decir, como ligada a la voluntad de ser útil a la transformación de las condiciones históricas, la palabra vida señala una sutil transformación, pues Candido ya no está pensando en la literatura como una fuente de conocimiento que permita comprender de manera adecuada la realidad, sino como una expresión condicionada por lo social, es decir, como una expresión de la vida social. La inversión de los términos es sutil pero significativa, pues implica que todas las obras, en rigor, deberían ser funcionales a su tiempo, pues todas son manifestaciones diversas de las condiciones de vida de una época. Así, podríamos deducir que el valor de la obra ya no está necesariamente supeditado al conocimiento de la realidad de manera adecuada. Por el contrario, lo que interesa a nuestro autor es entender cómo la realidad aparece retratada en la literatura, de qué manera ciertos conflictos están representados. La relación entre literatura y sociedad comienza a ser complejizada y aparecen ciertas problematizaciones que dan cuenta de las contradicciones implícitas en su proyecto. Candido comienza a someter sus propios principios a una revisión permanente y pese a su firme compromiso político, vemos ahora una creciente inclinación antidogmática que se hará evidente a lo largo de 1944.

19 Candido cuenta: "Mário de Andrade me dio un libro, un anuario de la Universidad de Columbia, en el que había artículos de René Wellek y de otros sobre los métodos literarios modernos, incluso uno de Cleanth Brooks titulado "The poem as an organism". Este pequeño artículo fue la revelación de la autonomía de la obra literaria" (Ruedas de la Serna 119).

$20 \quad$ Publicada en Folha da Manhã el 9 de enero de 1944. 
Una primera señal de la problematización de su propio método la encontramos en sus reflexiones acerca del significado de lo eterno en la literatura:

Acham, mesmo, que sacrifico o alcance da minha análise ao dirigi-la mais para o condicionamento da obra do que para o que se convenciona erroneamente chamar a sua essência. Ora, numa obra não há essência, porque uma obra é um lugar (sentido geométrico) de influências e de ressonâncias - da época, das condições sociais e da psicologia do autor (..) o que se chama de essência de uma obra não passa da hipóstase das suas condições (...) direi que dura aquilo que é condicionado: descobrir aquilo que condiciona é explicar a razão e a natureza do fenômeno de duração artística - embora seja mais estético e mais profundo aceitar o incondicionado (Textos 32-33).

El llamado "sacrificio" de su alcance crítico adquiere aquí una reformulación interesante. Aunque Candido aún no centra totalmente su atención en la factura interna de la obra y su crítica sigue siendo dependiente del contexto como factor determinante, su idea de lo condicionado como aspecto directamente relacionado con la "duración" se enriquece al ser concebida como una nueva forma de comprender lo que hasta ahora ha sido llamado "esencia", que no sería más que una "hipóstasis de lo condicionado". Hay aquí una propuesta acerca de cómo leer la sustancia inmortal de lo literario para hallar allí lo concreto, lo histórico-social y, en definitiva, la vida. Un nuevo horizonte de posibilidades críticas obliga a Candido a explicar la validez del método funcional y lo hace más consciente del peligro que este método conlleva: dar más importancia a los factores externos, es decir, sociales, que a la propia obra (Textos 34). Al cabo de un año de praxis crítica para Folha, Candido hace una advertencia que parece estar dirigida a sí mismo: es necesario mantener una clara distinción entre la función de la crítica y las de la historia y la sociología, en otras palabras; reconoce la importancia de un análisis que atienda al fenómeno de lo propiamente literario en términos de su autonomía. Su rechazo a la crítica impresionista y a su búsqueda de valores eternos no le impide admitir que existen otras formas de análisis que intentan comprender las obras literarias como un objeto autónomo, como es el caso del new criticism $^{21}$.

21 "um crítico norte-americano, historiando o romance inglês, mencionava o seu desejo de considerar a literatura como o que ele chama um "organismo", dizendo interessarem-lhe menos as ligações e o condicionamento da obra do que a sua realidade acabada e autônoma - 
Aunque Candido rechaza la concepción del medio social como un factor externo e indiferente, no desecha la idea de la necesaria autonomía de lo literario, más bien le parece que hay que entender cómo ese contexto no solo afecta a la literatura, sino que se transforma en su sustancia. Candido da a entender que no rechaza enteramente el análisis de la obra como un "organismo" 22 , sin embargo, no acepta el supuesto de que aquel organismo excluya necesariamente, en su propia organización interna, la realidad histórica y social: la realidad es la sustancia de lo literario, nos dice, aunque no nos explica cómo esa realidad deviene literatura. Añade que, si bien el análisis de la relación entre sociedad y literatura ha llegado a un punto de saturación en otras culturas, en Brasil ha estado prácticamente ausente de la crítica, por lo que urge incorporar este problema a los estudios literarios brasileños (Textos 35). El énfasis en la necesidad de una crítica funcional en Brasil nos muestra que la crítica literaria de perspectiva historicista no sería solo una opción política, sino además una necesidad interna del campo cultural brasileño, un campo que aún no está suficientemente diferenciado y que aún no ha hecho el trabajo de una investigación sostenida que permita comprender la trama histórica de su propio tejido cultural.

La transformación de la noción de función ayuda a Candido a salvar sus problemas entre ideología y estética, manteniendo intacto su compromiso político. Su crítica comienza a elaborar un deslinde entre estética y política que le permite investigar la función de la literatura en términos históricos sin caer en el rechazo estético de una u otra tendencia. Un ejemplo es la preocupación por la conformación de una tradición poética en Brasil que aparece

pelo mesmo motivo, acrescenta pitorescamente, por que, num quadro, a moldura lhe interessa menos do que a tela" (Textos 34).

22 La analogía entre obra y organismo proviene del ensayo de Cleanth Brooks "The poem as an organism". Ésta coincide con la analogía entre sociedad y organismo que establece la antropología funcionalista de Alfred R. Radcliffe-Brown. El crítico hará propia esta analogía, a la cual aplica una mirada dialéctica, fecundando de manera muy peculiar el método crítico de Cleanth Brooks. En el prefacio de 1972 para Literatura e sociedade, Candido hace alusión a esta analogía para explicar su peculiar uso del concepto estructura - concebida como la forma dinámica y peculiar de cada obra- y distinguirlo del estructuralismo lingüístico: "convém esclarecer que a acepção aqui utilizada foi desenvolvida com certa influência da antropologia social inglesa (tão atacada neste aspecto por Levi-Strauss) e se aproximaria antes da noção de "forma orgânica" relativa a cada obra e constituída pela inter-relação dinâmica dos seus elementos, exprimindo-se pela "coerência"” (10). 
en "Ordem e Progresso na poesia" 23 . Este artículo revela una maduración del proceso reflexivo en torno al problema de la tradición poética a través de una concepción dialéctica: la tradición como un juego de influencias y renovación que integra elementos nacionales y cosmopolitas. Aquí, Candido reflexiona sobre la autonomía de la tradición literaria brasileña que necesariamente entra en relación con las vanguardias europeas y con la experimentación verbal; todas cuestiones que no son vistas como algo necesariamente negativo. La integración de influencias extranjeras y la experimentación pueden valorarse históricamente en tanto elementos al interior de un movimiento general de desarrollo que va alterando el valor y el lugar de dichos elementos. Lo interesante aquí es la amplitud de la mirada de nuestro autor, que ve en el fenómeno de la influencia un elemento dialéctico de doble faz, encarnado en elementos de dinamismo y de estagnación. Los elementos rupturistas del modernismo, que hace un año eran valorados como fuerzas destructivas y peligrosamente individualistas, aparecen ahora en su faz positiva como elementos constructivos e inaugurales. El aporte de los poetas posteriores al modernismo, a su vez, ya no es visto necesariamente como la maduración de una tendencia y la superación de la fase experimental, sino que puede transformarse en una fuerza retrógrada cuando, incapaz de avanzar, se transforma en estancamiento. El valor de los distintos tipos de poesía adquiere un margen de relatividad, pues solo pueden ser comprendidos a partir del lugar que adquieren al interior de una tradición que posee un dinamismo interno propio y en alteración constante ${ }^{24}$.

Candido reconoce la influencia extranjera en figuras como Mário de Andrade o Manuel Bandeira y ve en esto una "falta da força da nossa própria poesia, ainda incapaz de criar valores realmente transmissíveis" (Textos 146). Sin embargo, es el coraje de estos mismos escritores y su fuerza inaugural para apropiarse de las vanguardias foráneas y ponerlas en diálogo con la experiencia de modernización brasileña y sus contradicciones internas, lo que permite abrir nuevos caminos que dan fruto tanto en escritores posteriores

24 Es probable que estas ideas sobre la tradición hayan recibido la influencia del famoso ensayo de T. S. Eliot "La tradición y el talento individual". Para 1944 Candido ya conocía la obra de Cleanth Brooks The Modern Poetry and the Tradition, donde están contenidas las ideas de Eliot acerca de la tradición en poesía (véase Candido, Última 5). El ensayo de Eliot es citado por Candido en su tesis de 1945, O método crítico de Sílvio Romero. Véase O método 179. 
como en las obras de madurez de aquella primera generación. Candido ve con alegría cómo en Vinicius de Moraes aparece una encrucijada de influencias brasileñas y extranjeras, donde el poeta está desarrollando aspectos de la tradición abierta por el modernismo. Asimismo, este cruce de influencias es visible en la obra actual de algunos poetas inaugurales como Mário de Andrade y Carlos Drummond, que ahora reflexionan sobre el individualismo exacerbado que puede producir el proceso de modernización y el vínculo con una comunidad histórica que tiene por delante la tarea de construir un futuro.

Ahora bien, una vez que el modernismo se constituye en tradición, pese a que ello implica el camino ganado de una autonomía y una retroalimentación al interior del propio campo cultural brasileño, dicha tradición ya sedimentada corre el peligro de transformarse en convención inerte. La poesía se estanca cuando se estabiliza en un orden establecido y su progreso depende enteramente del orden, pero solo como algo a ser subvertido mediante la creación de nuevos modos de poetizar: "porque a poesía vive justamente deste ultrapassamento contínuo, que faz com que a solução de hoje ceda lugar às necesidades de evolução, porque toda ordem só tem sentido em face do progresso que vai subvertê-la" (Textos 147). Los momentos de orden tienen para Candido dos caras. El orden representa el peligro del convencionalismo vacío, visible en los poetas que se apropian sin esfuerzo de las innovaciones estéticas del modernismo y caen en un facilismo estereotipado. La faz positiva se hace presente en la madurez que han adquirido los poetas inaugurales del modernismo, la que constituye un desarrollo ulterior al interior de aquel orden. Candido ve en este desarrollo un enriquecimiento ideológico, que implica la superación de una etapa de experimentalismo que ya no genera nuevas formas de comprender la experiencia de lo brasileño.

Para Candido, el problema de la tradición es un fenómeno complejo y en ningún sentido homogéneo. En el caso de la literatura brasileña ocurre que, al tener su origen en una lengua ajena, los momentos de progreso siempre corren el riesgo de exacerbar el aspecto cosmopolita de sus influencias, interrumpiendo el diálogo con un acervo nacional y perdiendo de vista aquello de lo cual este acervo es portador: la experiencia cultural brasileña. Pero ocurre que en los momentos de orden también se corre el peligro de debilitar la tradición literaria al convencionalizar los modos de expresión, que ya no entran en contacto con la realidad brasileña, renunciando con ello al esfuerzo de una búsqueda de nuevos medios de expresión que den cuenta de las vivencias actuales. Si bien Candido continúa siendo reacio a las vanguardias y ve en ellas el peligro del solipsismo, al situarlas desde 
una perspectiva histórica relativiza su valor al interior de la tradición, las ve como un fenómeno complejo que puede hacer germinar la poesía brasileña o ahogarla. La fuerza de la vanguardia termina por ser necesaria, es decir, cumple una función al interior de una línea de desarrollo del campo cultural. A su vez, el orden también aparece relativizado, al poder contener en sí la posibilidad del debilitamiento y la convencionalización estéril. Estamos lejos de la concepción simple de función social que Candido sostuviera hace un año. La perspectiva diacrónica parece abrir la puerta hacia una mediación dialéctica capaz de salvar la antinomia entre estética e ideología.

En cuanto al género narrativo, Candido intenta separar las aguas entre crítica funcional y crítica estética, donde la primera se hace cargo del sentido histórico de una producción cultural. Este intento es evidente en la nota sobre A quadragésima porta (1943) de Jorge Geraldo Vieira ${ }^{25}$. Candido afirma que esta novela encarna la visión de mundo de la burguesía brasileña y es un síntoma de que aquella clase, con su ideario y sus aspiraciones, continúa existiendo. La novela muestra el mundo de esa burguesía filo-europea, pero no es ni busca ser el retrato de una clase puesta en contexto al interior de un tejido social más amplio. Más bien es una encarnación de los ideales de esa clase: "Sonho de verão de um burguês recalcado, o seu romance é intrínseca e intimamente do ponto de vista ideológico um fruto do idealismo burguês que caracterizou o nosso século até a presente guerra" (A quadragésima 5) ${ }^{26}$. En suma, esta es una novela que consagra un conjunto de valores individualistas propios de la burguesía, disfrazados de búsqueda espiritual de un alma bella. La lectura de Candido es estrictamente funcional, lo que hace es mostrarnos el significado de la novela como la expresión ideológica y está claro que adopta un punto de vista marxista: la novela es revelada como síntoma y símbolo de una ideología de clase que bajo la excusa del desarrollo del individuo oculta un interés, al elidir el hecho de que esa búsqueda espiritual es posible solo para el selecto círculo de una élite. Candido no pierde la oportunidad de denunciar la ideología de clase implícita en la novela, sin embargo, siente la necesidad de realizar también un análisis estético, sin el cual su labor crítica

25 Candido dedica dos notas a esta novela, el 16 y el 23 de enero, que luego fueron publicadas con leves alteraciones en Brigada Ligeira con el título de "O romance da nostalgia burguesa".

26 En Brigada Ligeira, se agregan unas líneas: “... até a presente guerra, — com o seu cortejo de tabus: crença na supremacia do Espirito, subordinação a ele das coisas contingentes, redenção moral pela Arte, predominância das elites cultas" (30). 
quedaría incompleta ${ }^{27}$. El análisis sociológico-funcional le parece fundamental porque la propia afirmación del autor acerca del carácter ecuménico de su novela obliga a desenmascarar tal pretensión. Pero este esfuerzo le parece insuficiente pues la literatura, en tanto fenómeno artístico, debe ser juzgada bajo un criterio estético, de manera que decide hacer dos análisis paralelos. Y desde el punto de vista estético, Candido rescata esta novela por abrir un camino al interior de las letras brasileñas, iniciando una nueva posibilidad de expresión:

Mas, nessa busca de processos de expressão que lhe permitam uma aproximação mais efetiva com os valores, o sr. José Geraldo Vieira realiza uma das tarefas mais importantes da literatura que vem a ser a abertura de possibilidades, de vias de expressão que, se afastando de uma dada rotina violentam-na de certo medo e afirmam mais decididamente alguns aspectos do espírito, da sensibilidade ou do mundo, antes aprisionado pela estreiteza da convenção literária. $\mathrm{Na}$ moderna literatura brasileira (ao que eu saiba ou me lembre e descontando o jogo infeliz do sr. Jorge de Lima), o sr. José Geraldo Vieira guardará o mérito de ter rompido com o nexo lógico e aberto uma nesga para explorações mais ousadas da alma humana $(A$ quadragésima II 5$)^{28}$.

El rescate del valor estético de esta novela no solo da cuenta de la nueva estrategia de Candido, sino que nos muestra que, al igual que en caso de la poesía, está pensando en la idea de una tradición y en la necesidad de su constante renovación. Las novelas brasileñas también van formando una línea de continuidad que se alimenta internamente de las obras del pasado e incorpora nuevos caminos a través de las innovaciones presentes.

27 "Um romance não vale propriamente pelas suas diretrizes ideológicas nem pelo seu significado social, mas pela sua realização artística efetiva, que procurarei analisar no próximo artigo. No caso, esta tentativa de situação, que é sempre o meu ponto de partida em crítica, se impõe, porque o autor afirma ter querido fazer um romance ecumênico. Nascido do cosmopolitismo refinado da burguesia litorânea esse romance não é, como pretende o autor, ecumênico. Nem no sentido horizontal, de sobrepor as fronteiras dos povos, nem no vertical de se sobrepor as fronteiras duma classe" (A quadragésima 5).

28 En Brigada Ligeira, desaparece la referencia a Jorge de Lima y en lugar de "nexo lógico" habla de "apariencia sensible": "Na literatura brasileira ele guardara o mérito de ter levado a cabo a ruptura talvez mais pertinente com a aparência sensível, abrindo uma nesga para explorações mais ousadas da alma humana" (A quadragésima II 37). 
Otro ejemplo interesante de este deslinde entre la crítica funcional y la crítica estética es la nota "A roda do peru" ${ }^{29}$, que comenta la novela de Fernando Sabino A Marca (1944). Candido elogia la novela, equilibrada en su introspección y libre de esa manía egocéntrica y exhibicionista que encuentra en otras novelas del mismo tipo. Pero aprovecha la ocasión para pensar acerca del sentido histórico de la novela introspectiva y su presencia predominante en la literatura actual. No hay una condena estética a la novela introspectiva, sino un afán por entender su presencia en las letras actuales en un sentido histórico e ideológico. Sin embargo, Candido muestra cierta suspicacia frente a este tipo de novelas, pues le parece que los conflictos de la realidad son representados de una manera inadecuada. Por una parte, afirma que la novela introspectiva refleja claramente los conflictos del presente y que es expresión de una crisis que obliga al individuo a plegarse sobre sí frente a un mundo inhóspito. Pero también nos advierte que esta forma de reflejar la crisis es engañosa, pues los conflictos de los personajes aparecen como si fueran antinomias de carácter esencial y definitivo, cuando en realidad son dificultades momentáneas, producto de la falta de progreso de la personalidad. Las novelas introspectivas tienden a mantener la antinomia, en lugar de dar el salto dialéctico que permita superar esa realidad estática del sujeto cerrado sobre sí. La explicación de Candido deja ver a todas luces que para él la novela introspectiva tiende a construir una representación falseada de la realidad, pues insiste en la prolongación indefinida de contradicciones que, al aparecer como esenciales, permiten justificar la defensa de posiciones "já gastas", que frenan el proceso del "llegar a ser" mediante la oposición entre ser y no ser. Hay aquí, otra vez, una asombrosa cercanía con la estética de Lukács, específicamente con su concepción de la alegoría como una categoría estética que permite presentar como trascendente y esencial un conflicto históricamente determinado ${ }^{30}$. La reflexión de nuestro autor sobre las limitaciones de la novela introspectiva finaliza con la insistencia acerca de la perspectiva histórica de su análisis, que en ningún sentido debe equipararse a un juicio de carácter estético:

$30 \quad$ Véase Lukács, Significación 49. 
num tempo como o nosso, a linha excessivamente personalista do romance aparece, não raro, como defesa das posições já gastas da inteligência e da sociedade. Numa última palavra, -e usando termos rebarbativos, pelos quais me desculpo,- se opõe ao desenvolvimento dialético da personalidade e da sociedade, procurando brecar o vira-ser por meio do prolongamento indefinido das oposições do ser e do não-ser. Nisto não vai um julgamento de valor estético, mas antes histórico (5).

Pese al intento de mantener separados los juicios histórico y estético, es evidente que la desconfianza frente a la novela introspectiva se mantiene al subrayar el carácter limitado de su forma de presentar la realidad. Al proceso crítico en dos tiempos, que servía como estrategia para mantener la autonomía del juicio estético, se agrega aquí, subrepticiamente, un tercer momento, el del juicio epistemológico, pues en el examen de la novela introspectiva se cuela la exigencia de la adecuación de lo representado a una concepción específica de la realidad. Para Candido, la novela introspectiva es, en general, representante de un conjunto de ideas pertenecientes a una clase, como sucede en el caso de $A$ quadragésima, y es a la vez manifestación de una visión alienada de la realidad. La dificultad para conciliar el juicio estético y el juicio ideológico resulta evidente, pues la novela sigue atada a la obligación de representar la realidad de acuerdo con una concepción marxista del devenir históricosocial. En su interpretación histórica de la novela, Candido no logra salir de los márgenes estrechos de un método de interpretación marxista que relega el análisis estético a un segundo plano al imponerle a la literatura una configuración específica que, sin embargo, no se justifica en términos artísticos sino ideológicos. La supuesta separación de ámbitos críticos no es tal si la estética queda supeditada a las imposiciones del criterio funcional.

Sin embargo, una semana después de la nota sobre $A$ Marca, ocurre algo inesperado. El artículo "Língua, pensamento e literatura" ${ }^{31}$ sorprende al lector al constatar que Candido altera significativamente su propio pensamiento sobre las formas de representación en la novela:

Nos romances que se publicam todo o dia entre nós, podemos dizer, sem medo, que não encontramos a verdadeira exploração vocabular, a verdadeira aventura da expressão. Por maiores que sejam, os nossos 
romancistas se contentam com posições já adquiridas, pensando naturalmente que o impulso generoso que os anima supre a rudeza do material. Raramente nos é dado encontrar um escritor que, como o português Antonio Pedro, ou o Oswald de João Miramar, ou o Mário de Macunaíma, procura estender o domínio do vocábulo sobre regiões mais complexas e mais inexprimíveis, ou fazer da ficção uma forma de conhecimento do mundo e das ideias. Por isso, tive verdadeiro choque ao ler recentemente um livro publicado já há alguns meses, mas que só agora me caiu sob os olhos. Quero referir-me ao romance diferente que é Perto do coração selvagem, da sra. Clarice Lispector, escritora completamente desconhecida para mim (5).

El encuentro de Antonio Candido con la obra de Clarice Lispector marca un hito y Perto do coração selvagem pudo lo que no pudieron otras novelas: invertir el orden de subordinación entre estética y funcionalidad. Candido se rinde ante el poder creador de la prosa de Lispector, pese a su perspectiva eminentemente subjetiva. El crítico aborda ciertos aspectos de composición en la novela que le parecen más débiles, pero en ningún momento se detiene a cuestionarla en términos funcionales ni critica su modo de representación como una distorsión o como una forma estática. En su comentario ${ }^{32}$, Candido aún ve la obra literaria como una forma de producción de conocimiento $\mathrm{y}$, por lo tanto, aún considera su validez funcional desde un punto de vista epistemológico; pero ahora, por primera vez, se detiene a considerar que la forma de la novela puede crear un modo nuevo de ver y conocer el mundo. En un texto muy posterior, Candido cuenta cómo su encuentro con Lispector mudó sus perspectivas:

Clarice mostrava que a realidade social ou pessoal (que fornece o tema) se justificam antes de mais nada pelo fato de produzirem uma realidade própria, com a sua inteligibilidade específica. Não se trata mais de ver o texto como algo que se esgota ao conduzir a este ou aquele aspecto do mundo e do ser; mas de lhe pedir que crie para nós o mundo, ou um mundo que existe e atua na medida em que é discurso literário. Este fato é requisito em qualquer obra, obviamente; mas se ou autor assume mais consciência dele, mudam as maneiras de

32 Candido le dedica dos notas al debut de Clarice Lispector: "Lingua, pensamento e literatura", del 25 de junio, y "Perto do coração selvagem", del 16 de julio. Ambas fueron refundidas en Brigada Ligeira como "Uma tentativa de renovação". 
escrever e a crítica sente necessidade de reconsiderar os seus pontos de vista, inclusive a atitude disjuntiva (tema A ou tema B; direita ou esquerda). Isto porque, assim como os próprios escritores, a crítica verá que a força própria da ficção provém, antes de tudo, da convenção que permite elaborar os "mundos imaginários" (No começo XIX).

Antonio Candido termina sus contribuciones a Folha da Manhã con una serie de artículos dedicados a T.S. Eliot ${ }^{33}$. Estos artículos son el resultado de un largo proceso de lectura y reflexión motivado por el encuentro con la nueva crítica anglosajona, y marcan el tránsito de Candido hacia la crítica estética y el fin de la crítica funcional. La poesía de Eliot era famosa por su intelectualismo y su hermetismo, a tal punto que no eran pocos quienes lo tachaban de ser un esnob elitista. Todos estos eran elementos conflictivos para Candido y su criterio histórico funcional. La poesía de Eliot se constituye como un objeto artístico antirreferencial, pero es al mismo tiempo la retomada de una tradición poética anterior -la poesía metafísica- y echa mano a un acervo de antiguas tradiciones populares para tejer una crítica rotunda al vacío y a la vulgaridad de la vida moderna. El comentario de Candido es un largo ensayo que, a través de un análisis de los procedimientos poéticos de Eliot, pretende justificar su importancia y, en especial, su hermetismo, aunque esta justificación vaya a contrapelo de buena parte de los principios críticos que había afirmado hasta ahora.

Candido nos explica que la dificultad de Eliot se puede explicar por dos razones. En primer lugar, el poeta rompe con los patrones dominantes de la poesía anglosajona. Pero dicha ruptura no es un rechazo absoluto de la tradición, sino una recuperación de otro de sus momentos, el de la poesía metafísica del siglo XVII, lo que produce un enriquecimiento de la tradición poética en su conjunto, describiendo un proceso evolutivo de carácter dialéctico. El poeta construye su obra a través de una serie de procedimientos que explican la dificultad de su lectura, pero que también le permiten ganar una enorme riqueza en términos de su significado: "Todo o poema deve ser lido como que em quatro planos: a consciência das referências, a fim de aproveitar a riqueza das associações; o simbolismo psicossocial; o esforço de interpretação

33 La serie comienza con "Poesia inglesa" (24/12/1944), seguida de "T. S. Eliot I" (31/12/1944), "T. S. Eliot II" (07/01/1945), "T. S. Eliot III" (14/01/1945) y "T. S. Eliot IV" (21/01/1945). Un último artículo, “T. S. Eliot V”, no llegó a ser publicado, pues Antonio Candido renunció a su trabajo como crítico literario de Folha da Manhã por razones políticas. 
do mesmo em termos de mitologia; a unidade emocional que resulta desta convergência" (T.S. Eliot I 5). Los cuatro niveles que Candido identifica permiten entender la obra de Eliot como un sistema poético cuya articulación interna es la que le da su significado, tanto en términos estéticos como en su condición de expresión de la situación social del periodo de entreguerras.

Para Candido es muy importante explicar a sus lectores que la dificultad para comprender la obra de Eliot no se debe a un gesto elitista, sino que responde a una necesidad interna a la obra, pues es este el procedimiento que le da su riqueza y que le permite expresar de manera viva la experiencia moderna del siglo $\mathrm{xx}^{34}$. Candido comprende que no podemos exigir a la literatura que nos entregue una experiencia predeterminada, ya sea por nuestro gusto, por nuestra costumbre o por nuestras ideas políticas. La literatura constituye una experiencia de índole propia que exige una apertura por parte del lector y por parte del crítico. La serie de notas sobre Eliot termina con una reflexión acerca de la necesidad de esta experiencia de extrañamiento en relación con la tradición, la que solo avanza cuando se rompe con las fórmulas ya estabilizadas. Esta idea ya está presente en "Ordem e Progresso na poesia", pero se afianza luego de su lectura de Lispector para aparecer en esta nota como una certeza ya definitiva. La necesidad de nuevas formas poéticas debe ir a contrapelo de lo que el lector espera o de lo que los críticos ya han consagrado. Aquí volvemos a una concepción histórica de la literatura a través de la idea de tradición, pero al interior de esa tradición, la estética gana de manera definitiva su primacía, su derecho a ser el núcleo que le da sentido a la literatura y al cual se subordina cualquier otro tipo de análisis: "Erra quem acusa poesias, como a sua, de serem puros jogos de espírito. Pelo contrário, jogo de espírito é a exploração de velhos clichês, e a persistência em formas tacitamente aceitas pela sensibilidade automatizada do leitor (...) O hermetismo de Eliot revela, ao contrário, uma eclosão de todas as forças, um esforço emocional para criar algo novo, que representa uma riqueza poética genuína" (T.S. Eliot V 87).

La idea de un lector que, en su esfuerzo por comprender lo que esta poesía ofrece, participa del trabajo creador permite a Candido retomar, desde una

34 "Eliot convida o leitor a um esforço que lhe desagrada (...) No entanto, este desajustamento define a originalidade, e o caráter dos seus versos define aquele choque intelectual que nos obriga a sair da rotina e nos lançarmos na aventura a que nos convida o poeta. Define, para tudo dizer numa só frase, aquele "elemento de surpresa, tão essencial à poesia", de que nos fala o mesmo Eliot num dos seus ensaios" (T.S. Eliot V 87). 
perspectiva creadora, las reflexiones de Mário de Andrade sobre el artesanado como trabajo que vincula al artista con una tradición ${ }^{35}$. El virtuosismo es un malabarismo vacío de las formas, sí, pero solo en cuanto es repetición que ya no da cuenta de ninguna experiencia o de ningún sentido colectivo. Por el contrario, el verdadero artesanado lleva a encontrar formas nuevas de expresión que rompen con la tradición más inmediata y que son capaces de dotar nuevamente de sentido vivo al arte. Y el artesanado es un trabajo que es completado por el lector, que se hace partícipe del trabajo poético a través del esfuerzo de lectura. De este modo, Candido restituye el sentido del trabajo artístico, pero lo libera de sus compromisos con el sacrificio político. El artesanado puede y debe ser expresión de un yo, pero solo puede llegar a serlo realmente cuando consigue acuñar su forma propia, sin importar que esa forma lo lleve a romper con la vida o con una imagen predeterminada de la sociedad, con tal de construir un mundo autónomo que se sostenga por sí mismo. La literatura deja de ser sierva de la utilidad social y se transforma en creación, se valida por sí misma. Con esta visión llegamos al fin de la crítica funcional y al comienzo de una nueva etapa en la trayectoria de Antonio Candido:

Assim o hermetismo de Eliot (...) não quer dizer ressecamento nem impotência. É apenas indício da sua originalidade. Se não escapou do pedantismo, é porque este é quase uma fatalidade de toda obra que, por um excesso de requinte, um esforço de depuração estética, tende a cortar as pontes que a ligam com a vida, a fim de constituir-se num todo autônomo (Candido, T.S. Eliot V 88).

\section{BIBLIOGRAFÍA}

Brooks, Cleanth. "The poem as an organism: Modern Critical Procedure". English Institute Annual, 1940. New York: Columbia University Press, 1941. 20-41. Modern Poetry and the Tradition. New York: Oxford University, 1965.

Candido, Antonio. “A quadragésima porta (II)”. Folha da Manhã. 13 jan. 1944. 5. “A quadragésima porta”. Folha da Manhã. 16 jan. 1944. 5.

35 Véase la reflexión de Antonio Candido sobre la noción de artesanado a propósito de la publicación de $O$ baile das quatro artes (1943) de Mário de Andrade en la nota para Folha da Mahã "O artista e a sociedade", publicada el 6 de junio de 1943. 
"A roda do peru". Folha da Manhã. 18 jun. 1944. 5.

"Última nota". Folha da Manhã. 28 mayo. 1944. 7.

“Artista e sociedade". Folha da Manhã. 6 jun. 1943. 5.

"Ficção (I)”. Folha da Manhã. 4 fev. 1943. 5.

"Língua, pensamento, literatura”. Folha da Manhã. 25 jun. 1944. 5.

"Livros". Clima 1 (1941): 107-117.

"No começo era de fato o verbo". A Paixão Segundo G. H. Clarice Lispector. São

Paulo: ALLCA XX, 1997. XVII-XIX.

"Notas à margem de Donana sofredora". Clima 7 (1941): 96-100.

"O romance vendeu a sua alma”. Clima 6 (1941): 26-32.

"Perto do coração selvagem". Folha da Manhã. 16 jul. 1944. 5.

“T. S. Eliot - V (inédito)". Inimigo Rumor 9 (2000) 85-89.

“T. S. Eliot (I)". Folha da Manhã. 31 dic. 1945. 5.

"Vitaminose". Folha da Manhã. 23 maio 1943. 5.

Brigada Ligeira. Rio de Janeiro: Ouro sobre azul, 2004.

Literatura e sociedade. Rio de Janeiro: Ouro sobre azul, 2010.

O método crítico de Sílvio Romero. Rio de Janeiro: Ouro sobre azul, 2006.

Textos de intervenção. São Paulo: Ed. 34, 2002.

Dantas, Vinicius. Bibliografia de Antonio Candido. São Paulo: Ed. 34. 2002.

Errázuriz, Rebeca. "Antonio Candido y el problema de la tradición: el lugar de Oswald de Andrade”. Revista Chilena de Literatura 88 (2014) 77-94.

Lafetá, João Luiz. 1930: a crítica e o Modernismo. São Paulo: Ed. 34, 2000.

Lukács, Gyorgy. Significación actual del realismo crítico. México D. F.: Era, 1977.

Problemas del realismo. México D. F.: FCE, 1966.

Pontes, Heloisa. Destinos mistos: os críticos do Grupo Clima em São Paulo 1940-1968. São Paulo: Companhia das Letras, 1998.

Ramassote, Rodrigo Martins. A vida social das formas literárias: crítica e ciências sociais no pensamento de Antonio Candido. Tese para obtenção do Título de Doutor em Antropologia Social, Universidade de Campinas. 2013.

Ruedas de la Serna, Jorge. "Antonio Candido: Cómo y por qué escribí Formação da literatura brasileira". Casa de las Américas 268 (2012): 117-128. 